\title{
THE TRINIDAD CAVE ANT EREBOMYRMA (= SPELAEOMYRMEX) URICHI (WHEELER), WITH A COMMENT ON CAVERNICOLOUS ANTS IN GENERAL*
}

\author{
By Edward O. Wilson \\ The Biological Laboratories, Harvard University
}

In 1922 W. M. Wheeler described a new pheidologetonine ant, Spelaeomyrmex urichi, which he regarded as allied to Erebomyrma but sufficiently removed to justify the erection of a separate genus. The eleven syntypes, all minor workers, were collected in "Guacharo Cave," Trinidad, occupied by the oil-bird or "guacharo" (Steatornis caripensis Humboldt). Their pale color, minute eyes, and long bristly pilosity suggested to Wheeler that they represent a truly cavernicolous, i.e. troglobitic, species. In addition, Wheeler speculated that "the Texan E. longi Wheeler, which is certainly subterranean and has been taken only once (during a nuptial flight), is really a cavernicolous ant." In 1938, however, Wheeler reported the collection of workers of Spelaeomyrmex urichi by P. J. Darlington from leafmold in Cuba, thereby casting doubt on the status of the species as a troglobite.

Certainly no more likely troglobite than $S$. urichi has been found among the ants. Further information on its biology has promised to be of exceptional interest. In the course of field work in Trinidad in I96I, the present author undertook to rediscover the species. The first problem was to find the type locality. No fewer than six caves in various parts of the island harbor the guacharo and could correctly be called "Guacharo Cave." The itinerary of the collector, the late Prof. F. M. Urich, was not known. After the author had visited one cave, on the Spring Hill Estate, without success, Dr. David Snow, who was conducting an ecological study of the guacharos, suggested the Oropouche Cave, near Cumaca, as the most likely locality. A single visit to this cave, on April I 8, resulted in the immediate finding of two colonies of Spelaeomyrmex. Later, a surprising discovery was made: a colony collected from savanna forest at Bernhardsdorp, Surinam, in March I96I and first identified as Erebomyrma, was on second examination determined to be conspecific with Spelaeomyrmex urichi. These findings have shed new light on the generic distinctness of

*Manuscript received by the editor January 9, 1962. 
Spelaeomyrmex, on its status as a troglobite, and on the ecological singularity of cave ants in general.

\section{TAXONOMY \\ Erebomyrma Wheeler}

Erebomyrma Wheeler, 1903, Biol. Bull, 4:137-148, minor worker, queen, male. Type species (monobasic) : Erebomyrma longi Wheeler.

Spelaeomyrmex Wheeler, 1922, Amer. Mus. Novitates, 45:9, minor workers. Type species (monobasic) : Spelaeomyrmex urichi Wheeler. NEW SYNONYMY.

Following is a list of the known species of Erebomyrma, with attendant bibliography:

eidmanni Menozzi, in H. Eidmann, 1936, Arb. phys. Angew. ent. Berlin-Dahlem, 3:47-48, fig. V ( I-4), worker, soldier, queen. Type locality: Mendes, Rio de Janeiro, Brazil.

longi Wheeler, 1903, Biol. Bull., 4:137-148, figs. 1-5, minor worker, queen, male. Type locality: Denton, Texas.

morai Menozzi, I93I, Bull. Lab. Zool. Gen. Agr., Portici, 25:27 I272, fig. 7, worker. Original localities: Apaican, Vulcano; and San José (Costa Rica). Borgmeier, 1949, Rev. Brasil. Biol., 9:207208, figs. 8-9, "ergatogyne" (= soldier), second record from San José, Costa Rica.

nevermanni Mann, 1926, Psyche, 33:I03-104, worker. Type locality:

Hamburg Farm, Reventazon, Santa Clara, Costa Rica. peruviana Emery, 1905, Bull. Soc. Ent. Ital., 37:139, nota, queen. Type locality: Marcapata, Peru.

urichi (Wheeler), I922, Amer. Mus. Novitates, 45:9-I I, fig. IA-B, minor worker. Type locality: "Guacharo Cave," Trinidad. (Spelaeomyrmex urichi). Other records: Cuba, Yucatan, Surinam. The minor-worker characters cited by Wheeler as most strongly separating urichi from longi, and hence Spelaeomyrmex from Erebomyrma, are: larger head size; angulate (vs. round) humeri; proportionately larger first gastric segment; and minor features in the shape of the petiole, postpetiole, and legs. These differences probably signify a specific distinction between urichi and longi, but they are not great enough to justify a generic break, even by liberal standards. The synonymy is supported by the fact that the newly-discovered queen and male of urichi are closely similar to these castes in longi. One possible difference of generic magnitude, unknown to Wheeler, still remains: eidmanni, morai, nevermanni, and urichi are now known to 

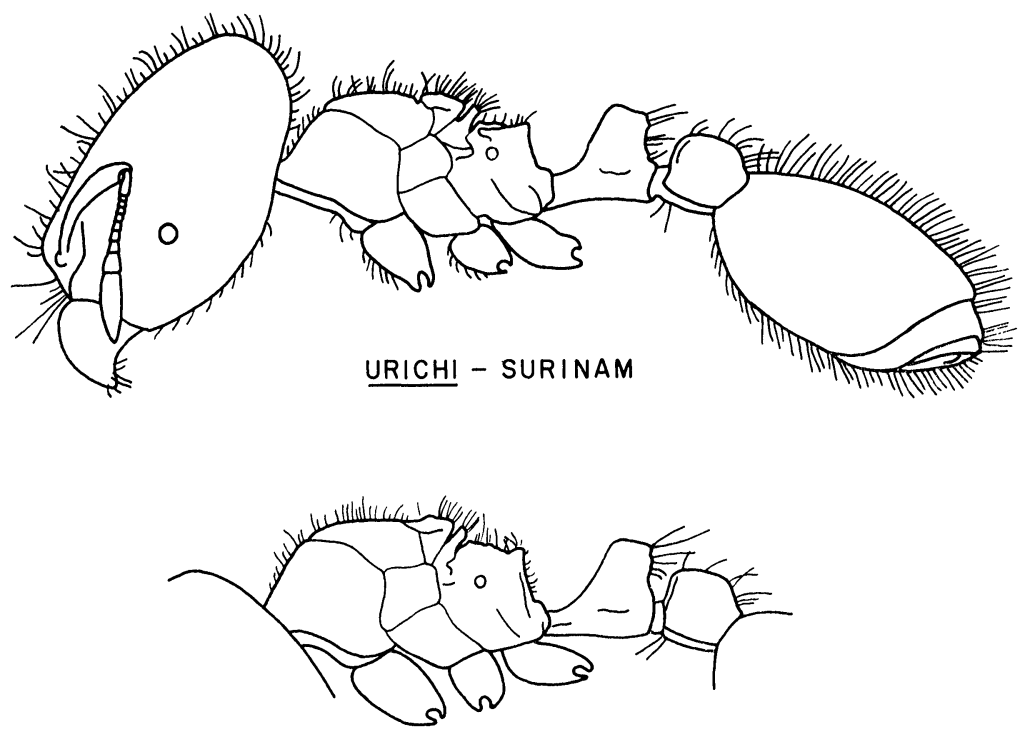

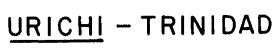

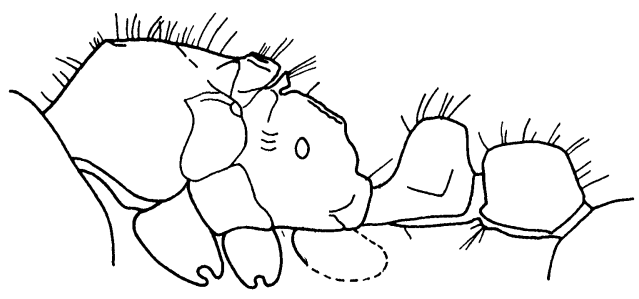

? NEVERMANNI - PANAMA

Figure 1. Soldiers of Erebomyrma urichi from Bernhardsdorp, Surinam, and Oropouche Cave, Trinidad, and E. ?nevermanni from Barro Colorado, Panama, showing variation in thoracic and pedicellar structure in this little known caste.

have a soldier caste, while none has been discovered in longi. However, longi is known from but a single collection, made under circumstances in which the scarce soldier caste could easily have been overlooked. It 
seems a fairly safe conjecture that longi soldiers will be discovered when whole colonies of that species are collected.

As just noted, the Oropouche urichi and a colony taken at Bernhardsdorp, Surinam, are considered conspecific. The minor workers of the two colonies are virtually identical. In the Oropouche soldier the anterior face of the petiolar node is slightly more inclined posteriorly (thus forming a greater angle with its anterior peduncle), the anterodorsal nodal angle somewhat more rounded, the propodeal angles are more pronounced and acute, and there are some differences in thoracic form and sculpturing (see text-figure). The Oropouche queens have slightly more developed propodeal spines and larger ocelli. In other respects the soldiers and queens appear identical between the two colonies.

Together, the Trinidad and Surinam urichi differ markedly from those in a series of Erebomyrma collected recently at Barro Colorado (W. L. Brown and E. S. McCluskey leg.) and tentatively determined as nevermanni Mann. The urichi minor worker has distinctly narrower, more erect propodeal spines; while the urichi soldier is much smaller and with more pronounced propodeal spines (text-figure).

\section{Ecology}

Trinidad. The Oropouche Cave is the source of the Oropouche River, which extends back into the cave as a clear strcam several meters in width. A colony of Erebomyrma urichi was found approximately 30 meters inside the cave on the bank of the stream, in very feeble light coming from the plainly visible cave mouth. Much of the ground was covered by guano dropped from the large numbers of guacharos nesting overhead. The arthropod fauna at this point was rich and diverse, consisting of ants [Mesoponera constricta Mayr, Odontomachus haematodus (Linné), and Solenopsis (Diplorhoptrum) tenuis Mayr], as well as the Erebomyrma, entomobryid collembolans, cave crickets, dermapterans, small flies, and mites. The ant species, other than Erebomyrma, have been collected outside caves in Trinidad. Mesoponera constricta, which was the most common forager in the vicinity of the Erebomyrma nest, was also a dominant ant along the trails through cacao plantations in the Cumaca area. Most of the other insects appeared to be troglophiles. Fifteen meters farther in, and in almost total darkness, a large Bufo marinus was found. In short, at the site of the first Erebomyrma nest, troglophilic (facultatively cavernicolous) animals predominated.

A second group of foraging Erebomyrma workers, almost certainly 
representing another colony, was encountered between 200 and 300 meters from the cave entrance. This spot was reached only after passing five major twists in the cave and was in apparently total darkness. It was the final outpost of the guacharo nests. Here there were no other ant species; in fact, none of the other three found at the first site ventured beyond the lighted portion of the cave. The arthropod fauna was sparse in species and biomass and consisted wholly of blind, white entomobryids, campodeids, isopods, and snails.

Just past the second site the cave ceiling dipped to within less than a meter of the stream surface, and the passage continued tortuously for another twenty meters or so. Beyond, the cave opened into a final oblong chamber before dipping beneath the stream surface. In this terminal room there were no guacharos; only bats had left a sprinkling of guano on the floor. A careful search revealed no Erebomyrma workers in the terminal chamber.

The nest at the first site, near the cave entrance, was located and excavated. It was enclosed entirely within a large, smooth shale slab partly buried in the cave soil and covered with a thin layer of dense clay. The rock was soft, naturally fractured, and could easily be broken apart with a steel trowel. Columns of workers were observed traveling from the guano piles to two entrance holes twelve centimeters apart on the upper edge of the rock. The holes were each about two millimeters in diameter, and each was surrounded by low, inconspicuous piles of excavated clay. The nest, located only a few centimeters below the surface, consisted of several flat, irregular cavities between five and ten centimeters wide and several millimeters in height. Probably the great majority of workers and all of the other adult castes were collected, both alive and preserved in alcohol. The sample, censused the following day, had the following composition: 547 minor workers, I soldier, Io dealate queens, IO males. Also present was a large quantity of brood, in all stages of development, including one male pupa. It was estimated that the entire worker population, including that part left foraging or missed in the nest, was not less than 600 and not greater than 1000 .

Previous to the excavation, the foraging workers were observed briefly. Workers were found up to $\mathrm{I} 1 / 2$ meters from the nest entrances, but the great majority was within a meter's radius. Most were hunting singly or moving in loose files through guacharo guano, just as Urich had found them forty years earlier. Workers returning to the nest converged in two separate files, which, judging from the precision 
with which they repeated each twist and turn, must have been following odor trails. Several were carrying objects: a mite, an entomobryid collembolan, and two unidentified arthropod eggs. The mite and entomobryid were freshly killed and had evidently been captured as prey. This conjecture is supported by the fact that Erebomyrma workers were most densely concentrated at points where large numbers of entomobryids occurred. Later, in captivity, workers fed readily on a wide variety of larger moths and flies presented to them, but only after these had been killed and cut open. In the original nest over a hundred unidentified globular objects resembling arthropod eggs were found piled with the brood. These were cared for by the captive colony in the artificial nest and may have been used sporadically for food, although direct feeding was not observed. Similar structures were found by Eidmann ( 1936) in the nests of Erebornyrma eidmanni.

Surinam. On March I4 a urichi colony was found in open, dry, second growth forest at Bernhardsdorp, near Lelydorp. It was nesting in a small rotting log partly buried in moist leaf litter in a wellshaded part of the forest. The population consisted of a single dealate queen, four soldiers, an estimated 500-1000 minor workers, and a large quantity of brood in every stage of development. Adjacent to the Erebomyrma colony was a large colony of the termite Armitermes minutus Emerson (det. A. E. Emerson). The Erebomyrma colony and a fraction of the Armitermes colony were placed alive in separate but interconnected artificial nests. Within a few hours after establishment Erebomyrma workers entered the still chaotic termite chamber and began carrying off eggs. They were unopposed by the much larger Armitermes adults, and in turn did not molest the Armitermes adults or nymphs. While the response of the Erebomyrma workers was clear-cut in this instance, it does not necessarily mean that the species is termitolestic on undisturbed Armitermes colonies in nature. The colony was kept alive for only a few days and there was no opportunity to extend the experiment. In this connection it is worth noting that Emerson (in Wheeler, I936) found evidence that Solenopsis (Diplorhoptrum) laeviceps Mayr collects and stores eggs of Nasutitermes cavifrons (Holmgren) and $N$. costalis Holmgren in British Guiana.

\section{BEHAVIOR}

The Trinidad colony was kept under observation in an artificial nest for two months and notes taken on selected aspects of behavior. The ethology of this species is of considerable interest because nothing 
has been recorded hitherto on Erebomyrma, and, in fact, very little information is available on the entire tribe Pheidologetonini.

The self-grooming movements of the minor worker are given as follows, according to the classification proposed recently for ants as a whole (Wilson, I962): (I) oral leg cleaning, (2) antenna wiping, (3) four-leg wiping, (4) three-leg wiping, (5) two-front-leg wiping, (7) head wiping (8) abdomen wiping (front legs). The queen repeated all of these movements and in addition (IO) metapleuron wiping, conspicuously missing in the worker. Other-grooming was as frequent as in most other myrmicines. The workers were especially attentive to the large queens, and a populous retinue followed each as it moved about. As many as six were seen riding on one queen's body at the same time.

Worker-to-worker regurgitation was frequent. The queens apparently were fed exclusively by worker regurgitation, and they never approached the prey. In several emigrations studied, adult transport was never observed. In one exceptional instance a worker carried a newly eclosed worked by its left middle and fore legs clumsily and a short distance over the brood pile, as though it were a piece of brood.

Discussion: The Ecology of Cavernicolous Ant Species

Penetration of caves by ants occurs chiefly in the tropics and is limited mostly to the dimly lighted (twilight) zone near entrances. The great majority of records belong to species that are obviously either trogloxenic (penetrating as foragers from nests outside) or troglophilic (facultatively cave-nesting). Further, these species are typically those that are among the most abundant, widespread, and adaptable members of the ant fauna in habitats outside the caves. For instance, a collection of ants made in 1959 in the Batu Caves, Malaya, by Mr. H. E. McClure and studied by the author, consisted primarily of three identifiable species [Bothroponera tridentata ( $\mathrm{Fr}$. Smith), Leptogenys diminuta (Fr. Smith), Pheidole javana Mayr] that are among the most widespread and common members of their genera in the Oriental Region. Wheeler (1924) records Triglyphothrix striatidens Emery from 400 feet inside the entrance of Siju Cave, Garo Hills, Assam ; this ant is a notably adaptable pantropical "tramp" and by far the most widely distributed Triglyphothrix. Of i 6 species recorded from Yucatan caves by Wheeler (1938), i 5 are identifiable, and of these I 3 have very extensive ranges in the New World tropics; most are known further to be abundant in various habitats. The remaining two species [Brachymyrmex cavernicolus Wheeler, Paratrechina (Nylanderia) pearsei Wheeler] belong to genera whose 
taxonomy and ecology are too poorly known to allow further generalization. Kempf (I96I) records Labidus coecus (Latreille) from "guacharo" caves in northern Peru and Venezuela. Both collections were made in zones of total darkness, at $90 \mathrm{~m}$. and $800 \mathrm{~m}$. respectively from the cave mouths. As Kempf points out, L. coecus is one of the commonest and most adaptable army ant species and ranges, at widely varying elevations, from the southern United States to northern Argentina. Santschi (1914) records eight species collected by Ch. Alluaud and R. Jeannel from caves at Tanga and Shimoni, Tanganyika. These can be roughly characterized as follows: Ponera dulcis Ford, widespread but known from only a few records; Leptogenys jeanneli Santschi, known only from the type collection but an unexceptional member of the epigeic falcigera group; Odontomachus haematoda L. var. troglodytes Santschi, probably the same as the very widespread, abundant African "haematoda" or "haematoda stanleyi" (?nec haematoda L. of the New World); Dorylus fimbriatus (Shuckard), very widespread and abundant; Monomorium rhopalocerum Emery subsp. speluncarum Santschi, probably equals rhopalocerum, a widespread and apparently relatively common species, collected at Shimoni only at a cave entrance; Strumigenys stygia Santschi, known only from the type collection but otherwise a morphologically unexceptional species of the rogeri group (see Brown, 1954); Miccostruma marginata (Santschi), known only from the type collection taken at cave entrance and not morphologically peculiar; Paratrechina ( Nylanderia) jaegerskioeldi (Mayr), very widespread and abundant. Thus this African cave fauna is made up of five more or less common widely distributed species together with three species still known only from the type caves. The latter exceptional group, however, belong to genera (Leptogenys, Strumigenys, Miccostruma) in which rare, local species are usual, so that no particular ecological significance can be attached to the fact that their known range is at present so limited.

Cave ants do not as a group possess the usual morphological modifications found in extreme cave dwellers. For the most part, they show no exceptional pigment or eye reduction when compared with their congeneric relatives, and, in the cases where their habits are known, they are no less epigeic in their foraging behavior. Conversely, the majority of the most highly modified hypogeic and subterranean tropical ant taxa are unknown from caves, e.g., extreme species of Amblyopone, Centromyrmex, Solenopsis (Diplorhoptrum), Tranopelta, Acropyga. We may conclude that the trogloxenes and troglophiles are characteristically generally adaptable rather than pre- 
adapted for cave life. Ants are not exceptional in this regard. Other adventitiously cavernicolous animal taxa are often very varied in their ecology; some other arthropod groups, such as the European copepods, resemble the ants in that the cave species are typically widely distributed on the outside (Hesse, Allee, and Schmidt, I95 I).

The question can now be raised, whether there are any ant species that are troglobitic, i.e. limited to caves. Erebomyrma urichi is clearly excluded on the basis of information just given, and the accumulated evidence makes it improbable that any other member of the genus is troglobitic. Paratrechina (Nylanderia) troglodytes Weber of Cuba, originally recorded from a shallow cave, has been shown to be a junior synonym of $P$. (N.) myops (Mann), which has been found in soil away from caves in two montane localities in Cuba (Brown, 1955). A related species, microps M. R. Smith, occurs in places remote from caves on Puerto Rico. Proceratium cavernicola (Borgmeier), described from a queen found in the Chilibrillo Caves of Panama, has been recognized as a synonym of $P$. micrommatum (Roger), known from several non-cavernicolous series collected in Central America and Cuba (Borgmeier, 1957; Brown, 1958).

There remain at least four ant species known only from single collections made in caves. Brachymyrmex cavernicolus Wheeler ( 1938 ) was found beneath a stone near the mouth of Balaam Canche Cave, Chichén Itzá, Yucatan. It is pale yellow in color and has small eyes, which perhaps suggest a normally cavernicolous habit. But it belongs to a genus the taxonomy of which is in outstandingly poor condition, so that the possibility exists that non-cavernicolous series have been recorded in the literature under other names, as in the cases of the Paratrechina and Proceratium species just mentioned. The African cavernicoles Leptogenys jeanneli, Strumigenys stygia, and Smithistruma marginata have already been discussed. They belong to otherwise non-cavernicolous groups and show no apparent morphological adaptation to cave life themselves. Clearly, until stronger evidence is produced, the existence of troglobitic cave ant species must be considered in great doubt.

Enlarging on this point, let us ask why there are so few (if any) troglobitic ants or, for that matter, troglobitic social insects of any sort. The following hypothesis is proposed. The reproductive unit in social insects is the colony, and it follows that natural selection operates on the colony as a unit. Further, the singly prefertilized mother queen of a monogynous colony ordinarily contains the whole of the transferable genetic material, and, since she stores the sperm of 
her mate (or mates), is genetically the equivalent of two or several individuals, the female and sexual consorts in a normal population of non-social animals. Hence, what may be referred to as the "equivalent size" of the reproductive population, $\mathrm{N}_{\mathrm{d}}$, in an idealized deme of social insects outside the nuptial season can be estimated as

$$
\mathrm{N}_{\mathrm{d}}=\frac{\mathrm{N}_{\mathrm{t}}}{\mathrm{N}_{\mathrm{c}}}(\mathrm{Q}+\mathrm{mQ})
$$

where $\mathrm{N}_{\mathrm{t}}$ is the total adult population of the deme, including workers, $\mathrm{m}$ is the average number of males that fecundated the queens assuming approximately equal sperm contributions, $Q$ is the average number of mother queens assuming approximately equal egg contributions, and $\mathrm{N}_{\mathrm{c}}$ is the average mature colony size. Thus in a cave deme containing I0,000 adult individuals with an average mature colony size of IOOO and single fertilizations of single queens, the reproductive population size equivalent would be only 20 . We may note that a deme of IO,OOO adults, the non-social condition, would perhaps be large enough and contain enough genetic variability to be stable and self-maintaining. Demes of this size are quite common in nature. But a deme-equivalent of 20 adults, the social condition, must be below the critical threshold or dangerously close.

In short, if species of social insects never become truly troglobitic it may be simply because they are unable to maintain sufficiently large cave demes. Due to limited habitable space, the Oropouche Cave could not have contained more than 20 colonies of Erebomyrma urichi and probably held considerably fewer. Erebomyrma colonies are sometimes polygynous, as we know from the single Oropouche example. If ten queens per colony is accepted as the upper limit, and each were assumed to be singly fertilized, the reproductive-population equivalent of the Oropouche Erebomyrma is calculated not to exceed 400. Since the excavated colony was the only obviously populous colony found, the actual equivalent was probably far less.

But let us suppose that social insects do occasionally become troglobitic; what characteristics might they be expected to have? In addition to the well-known morphological changes common to most troglophilic animals, there are several features of social structure that might be affected. There would likely be one or more of three devices to increase $\mathrm{N}_{d}$; namely, (I) decreased colony size, (2) increased polygyny, and (3) increase in m (polygamy). The Oropouche colony of Erebomyrma urichi was markedly polygynous, with the added result that the estimated $\mathrm{N}_{\mathrm{d}}$ of the colony was large (20). In fact, urichi, although not a troglobite, may be pre-adapted for marginal cave exis- 
tence. Finally, it is interesting to note that the predicted social modifications are just as likely to be developed in any ant species sufficiently ecologically restricted to be partitioned into very small demes.

\section{Acknowledgements}

The author wishes to thank Mr. Donald Dunston and Dr. and Mrs. John Buxton for their valuable assistance in exploring the Oropouche Cave. He is also indebted to Prof. A. E. Emerson for determining the termite prey of the Surinam Erebomyrma; and to Prof. W. L. Brown, Prof. K. Christiansen, Prof. W. S. Creighton, Dr. W. W. Kempf, and Mr. R. W. Taylor for critical readings of the manuscript. The field study was supported by a grant from the National Science Foundation.

BORGMEIER, $T$.

\section{References Cited}

1957. Myrmecologische Studien, I. An. Acad. Brasil. Cienc., 29: 103-128. BROWN, W. L.

1954. The ant genus Strumigenys in the Ethiopian and Malagasy Regions. Bull. Mus. Comp. Zool. Harv., 112:3-34.

1955. Nylanderia myops (Mann), new combination (Hymenoptera: Formicidae). Psyche, 62: 79.

1958. Contributions toward a reclassification of the Formicidae. II. Tribe Ectatommini (Hymenoptera). Bull. Mus. Comp. Zool.

Eidmann, H. Harv., 118 : 175-362.

1936. Ökologisch-faunistische Studien an sudbrasilianischen Ameisen. Arbeit. phys. angew. Ent. Berlin-Dahlem, 3: 26-48, 81-113.

Hesse, R., W. C. Allee, and K. P. Schmidt.

1951. Ecological animal geography. Second edition. John Wiley and Sons.

KEMPF, W. W.

1961. Labidus coecus as a cave ant. Stud. Ent., 4:551-552.

SANTSCHI, F.

1914. Formicidae in "Voyage de Ch. Alluaud and R. Jeannel en Afrique orientale, 1911-1912," (A. Schulz publ., Paris), Hymenoptera, II: 41-148, 30 fig.

WHEELER, W. M.

1924. Hymenoptera of the Siju Cave, Garo Hills, Assam, I. Triglyphothrix Striatidens Emery as a cave ant. Rec. Indian Mus., 26: 123124.

1936. Ecological relations of ponerine and other ants to termites. Proc. Amer. Acad. Arts Sci., 71: 159-243.

1938. Ants from the caves of Yucatan. Carnegie Inst. Publ., 491: 251255.

Wilson, E. O.

1962. Biology of Daceton armigerum (Latreille), with a classification of self-grooming movements in ants. Bull. Mus. Comp. Zool. Harv. (in press). 

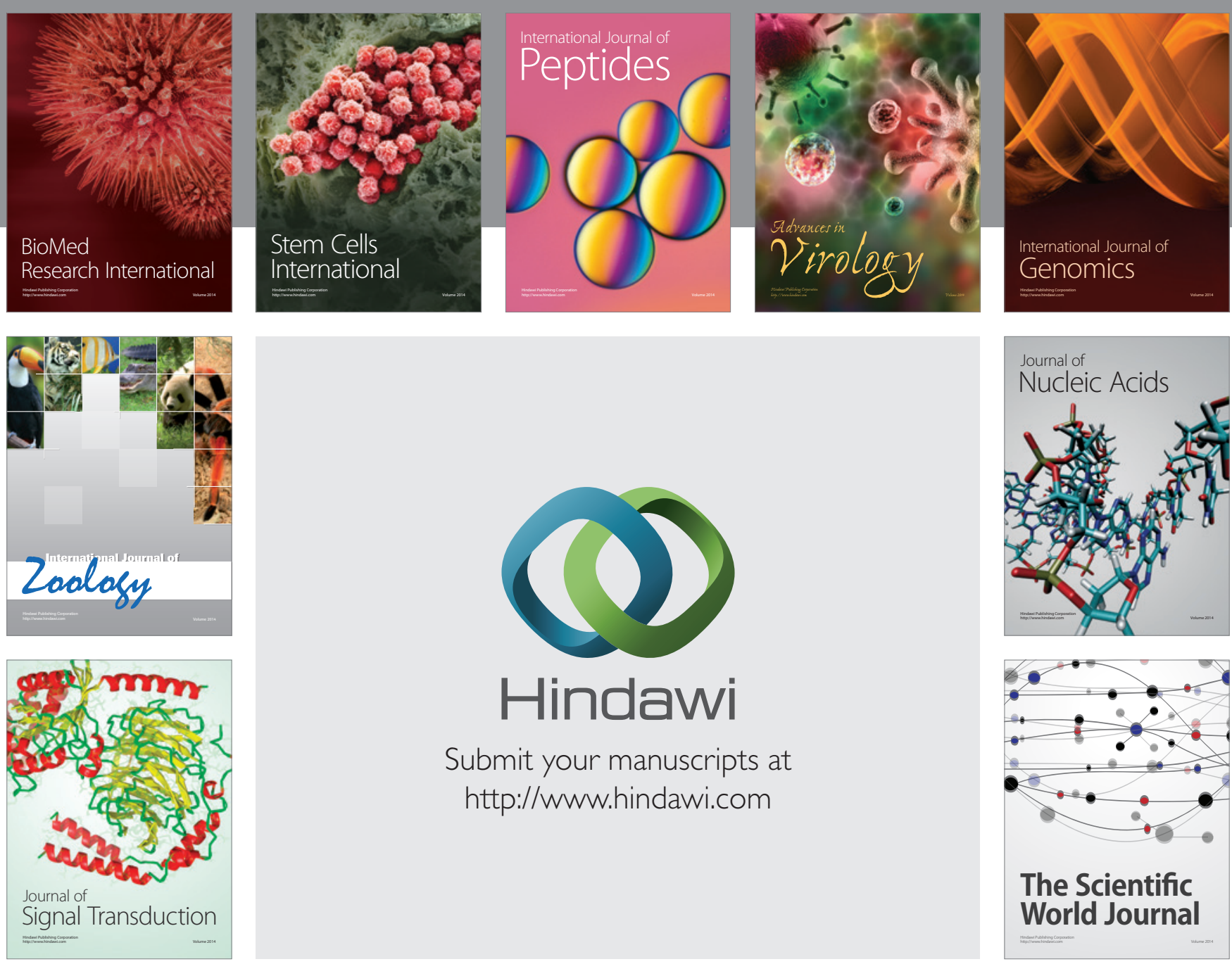

Submit your manuscripts at

http://www.hindawi.com
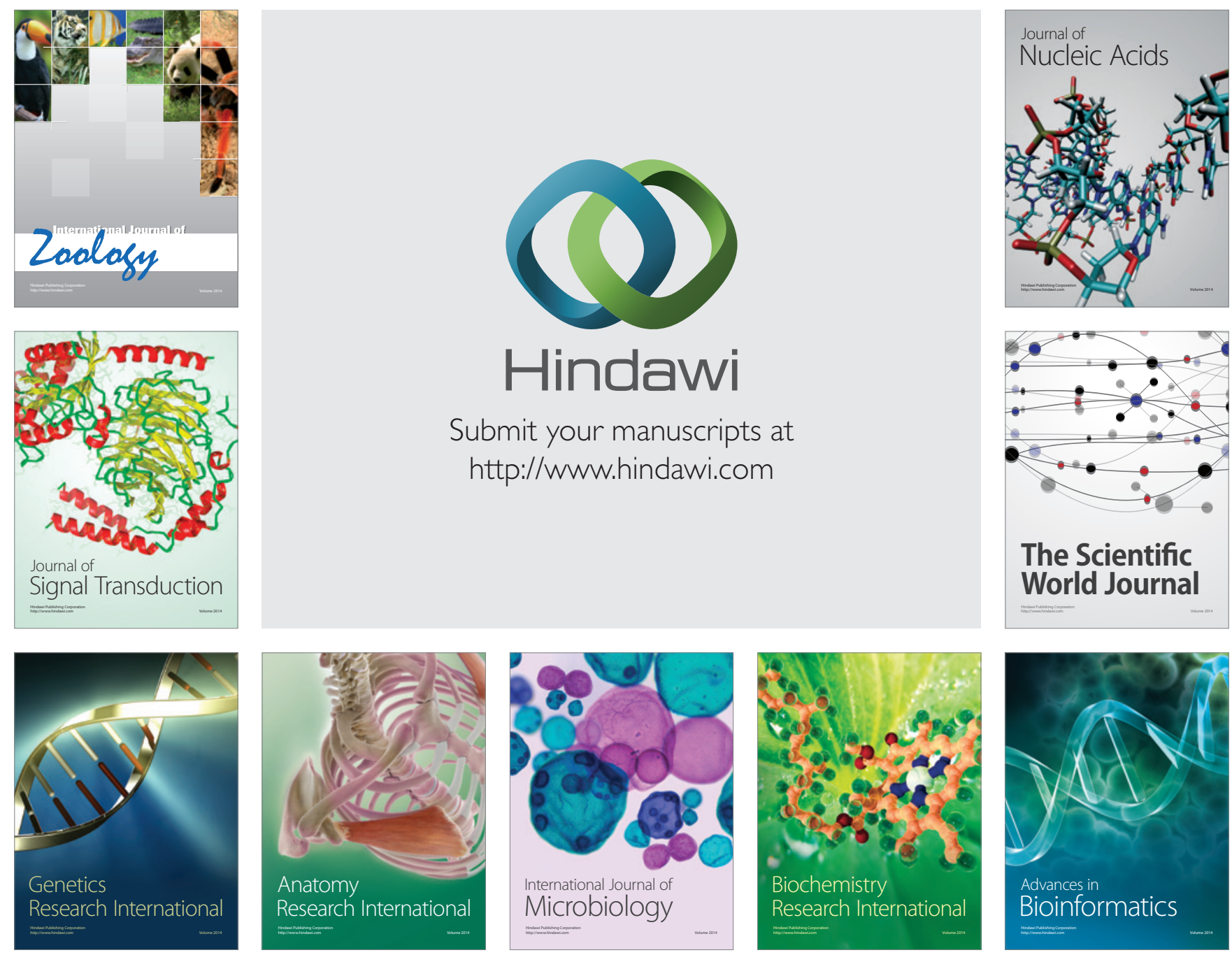

The Scientific World Journal
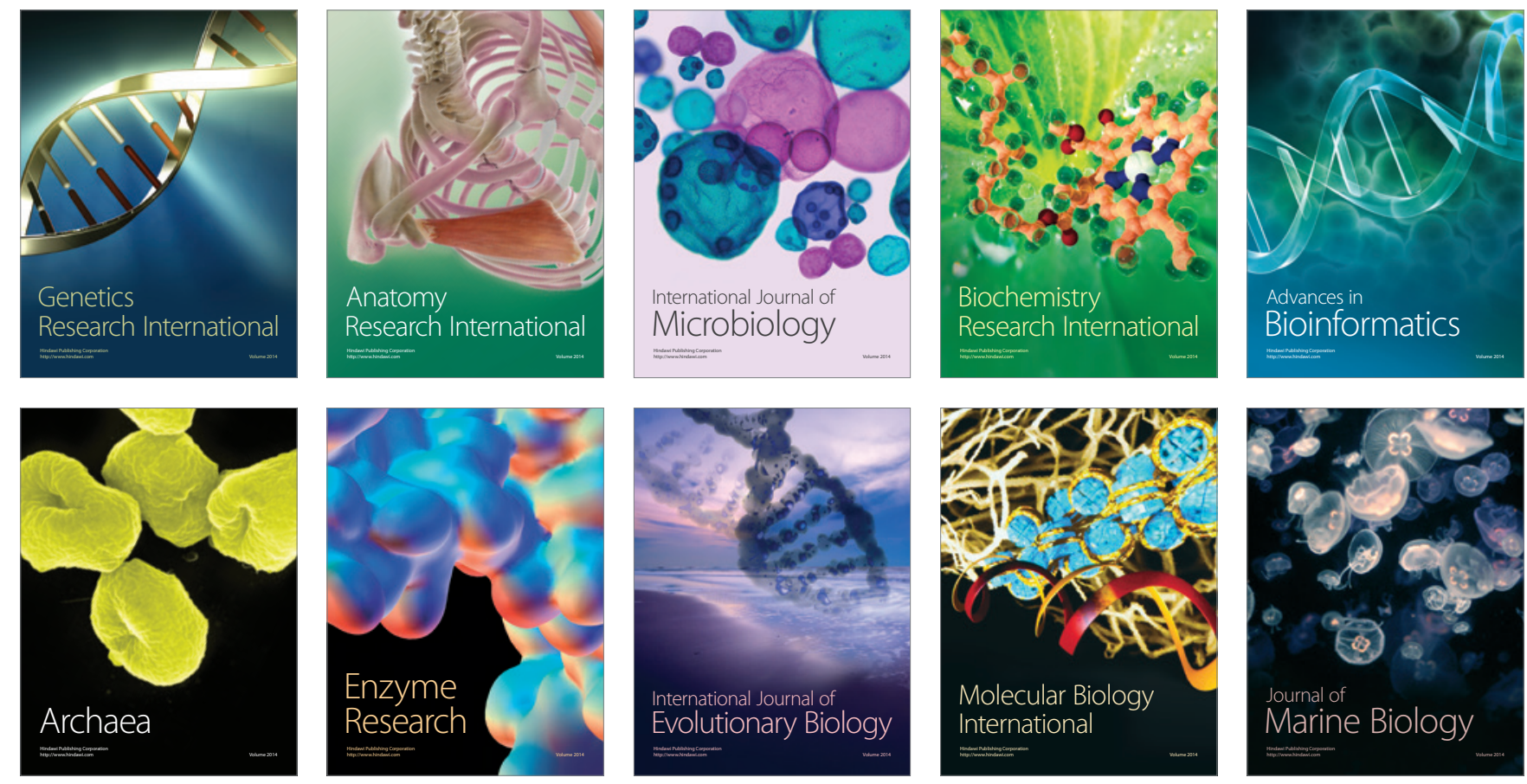